\title{
CONJETURAS EN TORNO AL CUERPO Y AL MOVIMIENTO
}

\section{SOME HYPOTHESIS CONCERNING BODY AND MOVEMENT}

Andrés Díaz Velasco ${ }^{1}$

Resumen

El presente texto es producto de la investigación en curso realizada al interior de la Maestría en Filosofía de la Universidad del Rosario (Bogotá). Pretende exponer dos concepciones complementarias sobre el axioma los hombres somos cuerpos en movimiento. Estas concepciones se plantean como sigue: por un lado, el cuerpo, como fenómeno múltiple, posee una naturaleza tetravalente; por otro, el movimiento, como expresión de la vida interactuante del mundo, es a su vez "expresado" de distintos modos (por ejemplo, modo práctico, técnico y habitual). En la primera parte, se hacen algunas alusiones a la naturaleza corporal y móvil del mundo. En la segunda parte, se desarrolla la indagación conceptual sobre el cuerpo y el modo práctico de movimiento. Y, finalmente, se concluye con una suscitación a nuevas indagaciones.

Palabras clave: Cuerpo, movimiento, práctica, técnica, hábito.

Abstract

This paper is a result of the research developed by Master of Philosophy at Universidad del Rosario (Bogota). It aims to explain two supplementary views of axiom men are moving bodies. These are proposed as follows: on the one hand, the body as a multiple phenomenon has a tetravalent nature; on the other hand, the movement as an expression of interacting life in the world in turn is 'expressed in different ways (i.e. practical, technical and habitual). The first part gives some hints to corporal and mobile nature of the world. The second part develops a conceptual inquiry of body and a practical way of movement. Finally, a conclusion with an invitation to further researches.

Keywords: Body, movement, practice, technique, habit.

Fecha de recepción: 22 de mayo de 2012

Fecha de aprobación: 19 de septiembre de 2012

1 Candidato a Magíster en Filosofía, Universidad del Rosario, Bogotá. Licenciado en Educación Físi51 ca, Universidad Pedagógica Nacional, Bogotá. Profesor ocasional de tiempo completo, vinculado a la Licenciatura en Recreación, Facultad de Educación Física, Universidad Pedagógica Nacional. Correo electrónico: andresdiazvelasco@gmail.com 


\section{Contexto del problema}

¿Cómo hacer para escribir si no es sobre lo que no se sabe, o lo que se sabe mal? Es acerca de esto, necesariamente, que imaginamos tener algo que decir. Sólo escribimos en la extremidad de nuestro saber, en ese punto extremo que separa nuestro saber y nuestra ignorancia, y que hace pasar el uno dentro de la otra. Sólo así nos decidimos a escribir. (Deleuze, 2006 p. 18)

El presente texto es un producto inacabado de la investigación en curso que, desde hace año y medio, hago al interior de la Maestría en Filosofía de la Universidad del Rosario. No solo continúa una línea de publicaciones en las cuales he problematizado (metafísicamente) alrededor del cuerpo y del movimiento -lejos de la posible disciplinariedad de la educación física, el deporte o la recreación; además, con un sentido renovador, reúne algunos planteamientos expuestos en dos ocasiones anteriores ${ }^{1}$. La continuidad y reelaboración de tales escritos, entonces, mostrará las distintas vías de indagación conceptual (y, valga decir, de contrastación existencial) figuradas hasta hoy.

La pretensión de este escrito es exponer dos concepciones complementarias sobre el axioma que hace tiempo he seguido, el cual puede expresarse sucintamente así: los hombres (si aún podemos insistir en este vocablo) somos cuerpos que se mueven en un mundo de cuerpos en movimiento ${ }^{2}$. Cuerpos moviéndose, simple y

1 Una de estas ocasiones, fue la participación que hice junto con el profesor Juan Manuel Carreño, y mis compañeras de estudio de entonces Viviana Betancur Chicué y Carolina Gaitán, en el Seminario Internacional de Epistemología y Enseñanza de la Educación Física (realizado en Bogotá por la Universidad Pedagógica Nacional del 10 al 14 de octubre del 2007), con una ponencia denominada "El cuerpo abierto: estudio de la técnica, la práctica y el hábito". La otra ocasión, fue la presentación del ensayo-proyecto como requisito para ingresar a la Maestría en Filosofía de la Universidad del Rosario; el texto en cuestión se denominó "Sobre la naturaleza tetravalente del cuerpo". La aclaración es necesaria porque, para el primer caso, debo agradecer a mis compañeros el permitirme modificar aquel texto colectivo y hacerlo parte de esta reflexión tan personal; y, para el segundo, porque aquí elimino, amplío o modifico varias de las afirmaciones presentadas ante los jurados.

2 En términos investigativos, con orientación políticometafísica, tal axioma toma la forma: el hombre y sus "asuntos" han de estudiarse desde la perspectiva de un "mundo" de cuerpos moviéndose. Espero que este escrito justifique,primariamente, tal formulación llana proposición que, no obstante, puede llevarnos por laberintos oscuros, terroríficos puentes colgantes y lodosos pastizales.

Ahora, las dos concepciones se plantean como sigue: por un lado el cuerpo, como fenómeno múltiple, posee una naturaleza tetravalente; por otro, el movimiento, como expresión de la vida interactuante del mundo, es a su vez "expresado" de distintos modos.

\section{De la naturaleza corpórea y móvil del mundo}

Poco importa si la mundanalidad implica cierta trascendencia (religiosa) de la naturaleza corpórea del mundo o, mejor, del mundo de aquí -como dice Jean-Luc Nancy (2003), conforme la pesadez del cuerpo-, ya que puede la forma etérea devenir el misterio revelado como Dios hecho carne (o bien como Jesús "resucitado") y, a su vez, puede declararse la extensión de la psique (la otra sacra trascendencia -moderna- de la materia) ${ }^{3}$. Por ello, la afirmación de un mundo de cuerpos no conlleva perplejidad ni, mucho menos, gran novedad. Ya Séneca, un contemporáneo del Jesús bíblico según el calendario gregoriano, lo había afirmado en respuesta a la pregunta de Lucilio (amigo íntimo suyo) sobre la naturaleza corpórea del bien. Séneca, el estoico, le responde (y debe disculpárseme lo largo de la cita):

El bien mueve al alma y, en cierta manera, le presta forma y contenido, cosas que son propias del cuerpo. El bien actúa, ya que aprovecha, y lo que obra es un cuerpo. Todo lo que es un bien del cuerpo es corporal: también lo es, pues, lo que es un bien del alma, ya que esta misma es un cuerpo. El bien

3 Nancy insiste en la importancia conceptual y práctica que para el "cuerpo" de la cultura occidental tiene la expresión latina hoc estenim corpus meum ("esto es el cuerpo mío" o "este es mi cuerpo" o "he aquí mi cuerpo"), que pronuncia Jesús en la última cena cuando toma el pan y lo reparte entre sus discípulos, ordenándoles continuar en memoria suya con esta celebración que es, a la vez, la anunciación de su entrega corporal como sacrificio ceremonial (en la crucifixión) y la dádiva alimenticia (pan espiritual) de la Eucaristía. Su insistencia, a mi juicio, es capital porque la expresión, que se repite hasta nuestros días, demarca tanto la relación occidental con el "cuerpo" (que tiene como modelo a Jesús en tanto que "encorporación" de Dios), como el procedimiento mismo por el que el cuerpo es "consagrado" al ser visto, tocado e ingerido. Por su parte, la "extensión de la psique" es tomada por Nancy de una nota póstuma (ya famosa) de Freud en la que afirma: "La psique es extensa: no sabe nada de ello". No me extenderé en más detalles porque en sí, tal acometido no es absolutamente crucial para este escrito. 
del hombre es forzoso que sea corporal, ya que el hombre lo es. 0 yo me engaño, o las cosas que alimentan y las que guardan y restituyen la salud son corporales: así mismo, por lo tanto, tiene que serlo su bien. Pienso que no dudarás que las pasiones sean cuerpos [...], por ejemplo, la ira, el amor, la tristeza, si es que no dudas que nos inmutan el rostro, que nos hacen fruncir el ceño, que nos dilatan el rostro, que nos hacen fluir la sangre. ¿Es que podrías creer que señales tan manifiestas del cuerpo pueden ser impresas por otra cosa que no sea un cuerpo? Si las pasiones son cuerpos, lo son también las enfermedades del alma [...] ¿No vez qué viveza presta a los ojos la fortaleza, qué fuerza de atención la prudencia, qué modestia y qué reposo la reverencia, qué serenidad la alegría, qué rigor la severidad, qué modestia la sinceridad? Podemos, pues, deducir que son cuerpos aquellas afecciones que trasmudan el color y el movimiento de los cuerpos y ejercen en ellos su imperio. ¿Por ventura podríamos dudar que es cuerpo aquello por lo cual pueda ser tocado un cuerpo? «Ninguna cosa puede tocar, ni ser tocada, que no sea cuerpo» según dice Lucrecio. Pero estas cosas que he mencionado no trasmutarían el cuerpo si no lo tocasen; son, pues, corporales. Y más aún, aquello que tiene fuerza, que puede impeler y constreñir, y retener e inhibir, es un cuerpo; $y$ ¿no es cierto que el amor retiene, que la audacia impulsa, que la fortaleza lanza y presta empuje, que la moderación frena y hace retroceder, que la alegría exalta y la tristeza abate? (Séneca, 1984 p. 139)

Como se ve, con ello no solo se afirma la naturaleza corpórea del mundo sino, además, su naturaleza móvil. No puede existir, como se ha dicho hasta el hastío, un cuerpo inmóvil -ni por vía de la física cuántica, ni por la física termodinámica, ni mucho menos por la epistemología amerindia o taoísta ${ }^{4}$. La forma en que esta movilidad es anunciada, en correspondencia con

4 Puede decirse que la "inmovilidad" es un invento para comprender el movimiento, pero no una "realidad" física o natural. Las ya famosas nociones de "movimiento constante" dadas por Heráclito y por Nietzsche son, a su vez, complementadas por Bergson, quien criticó severamente el estudio científico del movimiento debido a los "cortes" o "detenimientos" que deben hacerse del mismo. De acuerdo con él, analizar el movimiento como el desplazamiento de un punto "A" a un punto "B" resulta ser solo un análisis de la interrupción del movimiento y no del movimiento como tal. Por lo pronto, no daré más largas al asunto, ya que todas estas reflexiones las he venido acumulando en un texto que preparo para próxima publicación. Remito, entonces, a las alusiones que he hecho en escritos anteriores (Díaz, 2008, 2010). el cuerpo, obviamente aduce al tacto y a los "afectos" que de él se generan. Esto es, la relación conectiva: la naturaleza móvil del mundo como relación. Sobre este tema, decisivo es destacar ahora los planteamientos de Gregory Bateson (2002), quien presenta un estudio de la "relación" con base en lo que denomina recepción de información o aprendizaje caracterológico -entendido como la adquisición de la predisposición para dar respuestas automáticas a situaciones en ciertas circunstancias, como el sonar de un timbre-, pero, particularmente, en cuanto al aprendizaje acerca de sí mismo según los "cambios" que se pueden observar en el transcurrir de la vida.

Bateson concibe que los cambios que se perciben sobre uno mismo (por ejemplo, cambios de ánimo, o cambios de "autopercepción", para usar una noción psicológica), no dependen exclusivamente de uno sino que, por el contrario, son solo posibles por la precedencia de la relación. Habría pues cierta unicidad entre el aprendizaje y la interacción, por la que el "sí-mismo" viene a ser una suerte de "resultado" (palabra que no usa Bateson) de la relación.

El aprendizaje de los contextos de la vida es una cuestión que debe ser examinada, no internamente, sino como relación externa entre dos seres. Y una relación es siempre un producto de doble descripción. Es correcto (y constituye un gran avance) comenzar a pensar en los dos bandos que participan en la interacción como dos ojos, cada uno de los cuales da una visión monocular de lo que acontece, y juntos dan una visión binocular en profundidad. Esta doble visión es la relación. La relación no es interior a la persona individual. No tiene sentido hablar de "dependencia", "agresividad", "orgullo", etc.; todas estas palabras tiene su raíz en lo que ocurre entre personas, no en talo-cual-cosa presuntamente situada dentro de una persona. Hay, sin duda, un aprendizaje en el sentido más restringido. Hay cambios en A y cambios en B que corresponden a la dependencia-protección de la relación. Pero la relación viene primero: es precedente. (Bateson, 2002 p. 147)

De este modo, se reafirma la naturaleza corpórea y móvil del "mundo"; y, gracias a que los argumentos se sostendrían por la referencia directa a nuestra propia existencia, adquiere otro sentido hablar de cuerpo (incluso biológico) y movimiento (incluso fisiológico). La diafanidad y la simpleza del axioma mencionado más atrás, entonces, empiezan a ser cuestionadas; por ello, se hace necesario recorrer y ahondar sus circunvoluciones. Lo que viene a continuación, entonces, es una 
aproximación conceptual a las implicaciones existenciales de la corporalidad móvil (maquínica), de acuerdo con la multiplicidad propia del cuerpo -que ya no funge como aparato animado por alguna otra "cosa" de naturaleza distinta- y con la riqueza analítica del movimiento -que ahora comprende más fenómenos que la "operatividad" y, en cambio, encadena el sentido de la interdependencia de los cuerpos (lo que podríamos denominar el deseo) con el azar de las relaciones indeterminadas-.

\section{Sobre la naturaleza tetravalente del cuerpo y el modo práctico de movimiento}

Para abordar el quid de nuestro asunto, el avance en la indagación conceptual sobre el cuerpo y el movimiento, resulta imprescindible puntualizar la orientación general de la investigación. En primer lugar, habiendo asumido el cuerpo como un "fenómeno múltiple" (Díaz, 2009), hemos discernido cuatro valencias que le son propias o "naturales". Valías, capacidades de combinación y "características" del cuerpo por las que no solo se manifiesta sino que es vitalmente apropiado.

En segunda instancia, comprendido el movimiento como una "realidad" existencial ineludible, hemos consentido modos de moverse -por lo pronto equivalentes a usos del cuerpo- que además de ser sus aproximaciones conceptuales (en el sentido de Deleuze y Guattari, 2005), son sus particulares "maneras" de "expresión" (performativa). En lo que sigue veremos, con algo más de detalle, de qué se trata todo esto.

\section{Vivencia y existencia}

Basta con ver Avances recientes en la teoría del cuerpo, del sociólogo Bryan Turner (2007), para evidenciar cómo entre el siglo XIX y el XX se emprendió un extensísimo estudio alrededor del cuerpo, bien porque había una relación estropeada desde el principio de la historia filosófica de Occidente (según apuntes de la Escuela de Fráncfort que cita Turner), bien porque fascinó el hecho de que ningún problema (sexual, ético, político, estético, histórico, educativo...) puede realmente escapar de él, ni por la vía de la obviedad ni por su demérito.

El cuerpo, pues, se erige en nuestros días como catalizador de todos los intentos por comprender el "mundo". No obstante, parece todavía difícil tanto esquivar los lugares comunes (por ejemplo, las famosas dicotomías cuerpo-mente, naturaleza-cultura, instinto-razón, materia-forma, tangible-intangible, biológico-socioló- gico, cuerpo-corporeidad, etc.), como "conceptuarlo" sin quedar preso de la "mismidad" o "subjetividad" que, supuestamente, vendría a reemplazar con una suerte de unicidad (del ser humano) cualquier pretensión dualista. No hay salida que complazca, ni procedimiento satisfactorio. Este estudio -programa de la modernidad- deja ver entonces que, en palabras de Nancy, "El cuerpo" es nuestra angustia puesta al desnudo" (2003 p. 10).

Ahora bien, con pretensiones y orientaciones bien distintas a las convencionales y con base en Antonin Artaud (según lo admiten), Deleuze y Guattari elaboran un concepto extraordinario del cuerpo en cuanto tal y en oposición al organismo -no como existencia biológica sino como organización orgánica del cuerpo-, por el cual otras consideraciones ontológicas se abren. Estos autores dicen: "El cuerpo es el cuerpo. Está solo. Y no tiene necesidad de órganos. El cuerpo nunca es un organismo. Los organismos son los enemigos del cuerpo" (1997 p. 163; cursiva del original). Tal como vemos, la apuesta se trata de diferenciar, desde el propio "cuerpo cultural" de Occidente, la organización del cuerpo y el cuerpo no organizado (o desterritorializado). Es decir, dos "planos" o "campos" próximos, simultáneos, que configuran la condición de lo viviente y lo existente ${ }^{5}$.

Por un lado, el cuerpo de la vivencia: "Conexión de deseos, conjunción de flujos, continuum de intensidades" (Deleuze y Guattari, 1997, p. 166); y, por otro, "el orden del soma [que] hace caer abajo toda la escala intensiva" (Ibíd.). Por un lado, una vida o la inmanencia, el cuerpo spatium, virginal, "pura conciencia de corriente a-subjetiva, conciencia prerreflexiva impersonal, duración cualitativa de la conciencia sin yo" (Deleuze, 2005, p. 11); y por el otro, la existencia, la cultura, el sujeto, el territorio, cuerpo extensio, cuerpo estriado o estratificado. Así, cuerpo sin órganos ( $\mathrm{CsO}$ ) poblado por inten-

5 Los dos planos son distinguidos claramente por Deleuze en sus Diálogos con Claire Parnet: "Por un lado un plano que podríamos llamar de organización, que concierne a la vez al desarrollo de las formas y a la formación de los sujetos, y que es, si se quiere, estructural y genético". Este plano "no viene dado por sí mismo, sino que siempre debe ser deducido, inferido, inducido a partir de lo que él organiza [porque] existe también otro tipo de plano que es completamente distinto: el plano de consistencia [el cual] no conoce más que relaciones de movimiento y de reposo, de velocidad y de lentitud, entre elementos no formados, relativamente no formados" (2004, p. 104). Y no se puede decir que uno vaya primero que el otro, “el cuerpo sin órganos no es 'anterior' al organismo, es adyacente a él” (Deleuze y Guattari, 1997, p. 168). 
sidades, y su opuesto, "esa organización de los órganos que llamamos organismo" (Deleuze y Guattari, 1997, p. 163).

El plano de la organización deshecha: cuerpo como "conjunto de válvulas, cámaras, exclusas, recipientes o vasos comunicantes" (Deleuze y Guattari, 1997, p. 158); y el plano de la organización (rehecha) como vastedad de organizaciones que lo pliegan, lo atan, lo axiomatizan en tanto que "cuerpos culturales". Por un lado, espacio liso y, por el otro, espacio estriado; "mientras que en el estriado las formas organizan una materia, en el liso los materiales señalan fuerzas" (Deleuze y Guattari, 1997, p. 487). De manera tal que:

El organismo no es en modo alguno el cuerpo, el $\mathrm{CsO}$, sino un estrato en el $\mathrm{CsO}$, es decir, un fenómeno de acumulación, de coagulación, de sedimentación que le impone formas, funciones, uniones, organizaciones dominantes y jerarquizadas, trascendencias organizadas para extraer de él un trabajo útil [...] El CsO grita ¡me han hecho un organismo! ¡Me han plegado indebidamente! ¡Me han robado mi cuerpo! (Deleuze y Guattari, 1997, p. 164)

Así, pues, tenemos dos planos -campo trascendental, puro plano de inmanencia, y campo existencial o "intersubjetivo"- que, sin duda, implican mucho más que aquel cuerpo sensible "rescatado" por los estudios subjetivistas (educativos) del "yo soy mi cuerpo". Dos planos que, en términos concretos, o mejor, en relación con el lenguaje filosófico del que nos hemos apropiado, dicen el cuerpo en su naturaleza tetravalente. En un sentido, la multiplicidad del cuerpo depende, o es deudora, de la diferencia de ambos campos. Este sentido precisa el espacio liso como lo indeterminado o como vivencia (velocidad infinita) y, a su vez, el espacio estriado como lo determinado o como existencia (velocidad finita). De un lado y de otro, el cuerpo es múltiple: multiplicidad de organizaciones y multiplicidad propia de lo indeterminado. En otro sentido, el cuerpo hace que los planos converjan en él como desembocadura de cuatro ríos. De acuerdo con esto, los cuatro ríos se complementarían como valencias esenciales al cuerpo: 1) cuerpo sin órganos, 2) cuerpo cultural, 3) cuerpo singular y 4) cuerpo sujeto.

Las dos primeras valencias comprenden el universo "colectivo" del cuerpo para ambos planos. El cuerpo sin órganos no puede ser interpretado como un asunto individual: no solo hay muchos cuerpos sin órganos (hipocondríaco, paranoico, esquizofrénico, drogado, masoquista...), sino que cada uno es, intrínsecamente, muchos: "Siempre hay un colectivo, incluso si se está solo" (Deleuze y Guattari, 1997, p. 158). Igualmente, la lógica de producción del cuerpo cultural designa un grupo (que lo comparte y que por interacción lo expresa). Por su parte, las dos valencias restantes remiten a la "singularidad" innegable de la existencia corporal, advertida -sobre todo- en el nacimiento y en la muerte ${ }^{6}$.

Ahora bien, la relación entre estas cuatro valencias es la siguiente. Primero, la organización del cuerpo sin órganos sucede por la interacción significativa o, mejor, de significaciones compartidas, en las que hay homología entre la estructura y funcionamiento del cuerpo (como microcosmos) y la estructura y funcionamiento de la sociedad (en términos amplios -lenguaje, producción económica, organización política, entre otroscomo macrocosmos).

Por ello, la cultura no es una simple "mentalidad" respecto al "mundo de las cosas", sino una forma de vivir, una forma de estar-siendo-cuerpo-en-el-mundo, una forma de moverse: cuerpo cultural (López Austin, 2008; Pinzón y Suárez, 1992). En segundo lugar, la organización del cuerpo singular es un producto de esta intersubjetividad en la que, además, hay una red inextricable de poder (acciones que modifican acciones, en el sentido de Foucault) que lo atraviesa: la organización del cuerpo singular es el cuerpo sujeto, carnalidad significada, "forma de ser en nuestros cuerpos" (McLaren, 1997, p. 89). Finalmente, también un proceso de des-organización (o desterritorialización) por el que del cuerpo cultural se hace un cuerpo sin órganos y del cuerpo sujeto se llega a un cuerpo singular. Por ello, el cuerpo sin órganos "nunca es el tuyo, el mío... Siempre es un cuerpo" (Deleuze y Guattari, 1997 p. 168). El cuerpo sin órganos es la inmanencia absoluta en sí: "No es dentro de algo, no está en alguna cosa, no depende de un objeto ni pertenece a un sujeto" (Deleuze, 2005 p. 12). Y, así mismo, el cuerpo singular es una vida.

6 Sin temor alguno respecto del solipsismo que suele presentarse (y objetarse) frente a los problemas que demanda la "singularidad", además del nacimiento y la muerte, también el dolor y la "experiencia" del "mundo" son temas filosóficos importantes. Es clásico ya el análisis de Wittgenstein respecto al "dolor de muela" que únicamente "yo" puedo sentir; y, así mismo, el análisis sobre la mirada en Sartre y MerleauPonty (es a "mí" al que miran). Por otra parte, por vía distinta a las determinaciones sociales de género, con Viveiros de Castro (2006) se puede investigar cuál es la forma particular de "experimentar" el mundo con cierto tipo de morfología (vagina en vez de pene, garra en vez de mano, etc.). 
Con un relato novelesco de Dickens, en el que un "mal tipo" agonizante pierde su subjetividad (la manera en la que sus vecinos lo tratan y en la que él mismo se ve), Deleuze expone esta última consideración del siguiente modo:

La vida del individuo ha dado lugar a una vida impersonal, y sin embargo singular, que extrae un puro acontecimiento liberado de los accidentes de la vida interior y exterior, es decir, de la subjetividad y de la objetividad de lo que acontece. "Homo tantum" [...]. Es una haeceidad, que no es ya de individualización sino de singularización: vida de pura inmanencia, neutra, lejos del bien y del mal, puesto que sólo el sujeto que la encarnaba en medio de las cosas la volvía buena o mala. La vida de tal individualidad deja paso al provecho de la vida singular inmanente en un hombre que no tiene más que apellido, siempre que no se confunda con ningún otro. Esencia singular, una vida... (2005 p. 13)

Simultáneos, en cierto sentido, complementarios: ambos planos, y las cuatro valencias, se "interceptan" en lo que llamamos experiencia corporal (Díaz, 2007; 2011); ella es el nodo, el proceso de estratificación o su construcción, el punto de pliegue, el puente, el tránsito, la juntura. La experiencia corporal no es la experiencia del cuerpo (ni por el lado "externalista" de la sensación, ni por el lado "internalista" del conocimiento o habilidad adquiridos), sino, invirtiendo a Foucault, se trata de la experiencia de ponerse dentro de sí, el "adentramiento" del sujeto, la "imbricación" en el grupo. El cuerpo singular se subjetiva dada una experiencia corporal, el cuerpo sin órganos se organiza (como cuerpo cultural) al darse una experiencia corporal. Lo que subyace, por tanto, al cuerpo sujeto y al cuerpo cultural es una experiencia corporal en tanto que su proceso de producción ${ }^{7}$.

7 Ni en este, ni en escritos anteriores, intento dar una definición tajante (cual diccionario) de la experiencia corporal. Por el contrario, siempre he buscado hacer de la expresión un "concepto" que no es alcanzable sino en sus contornos, en sus proximidades, en los "discursos" que posibilita. El concepto no está dado, ni es siquiera deseable darlo por hecho, siempre que se quiera seguir estudiándolo y aprovechándolo para diversos problemas que surgen in media res. Lo aquí expuesto, entonces, junto con lo contemplado en los artículos citados, ha de verse como un esfuerzo de "invención" tanto como de "intervención" en un problema muy concreto respecto a la producción de subjetividad y de formas de vivir, de acuerdo con la ya vieja y acuciosa denuncia de la ingravidez del "Yo".
Interacción y modo práctico de movimiento

A pesar de la dificultad de asirla, la experiencia corporal no es una expresión sin "referencia" o, en otras palabras, responde perfectamente al "principio de existencia" y, por tanto, al de "identificación" (Searle, 2009). Afectar y ser afectado, ejercer el poder (del cuerpo) y participar en una colectividad de cuerpos son la base tripartita de una experiencia corporal. Por tanto, solo a través del estudio del movimiento podemos dar con aquello a lo que refiere. Ahora bien, lo que se muestra a continuación son solo algunos de los aspectos en los que se ha centrado este estudio, sabiendo que con ello, de algún modo, se abre la posibilidad de ir más allá de las imputaciones que se le siguen haciendo.

En principio, resulta de mucho interés la noción de interacción. El movimiento supone lo que hemos denominado relación conectiva, y que esta, como se mostró atrás con Bateson, supone también la reciprocidad. Ahora, por "interacción", para mantenernos en el uso común y corriente, se entiende la acción que se ejerce recíprocamente entre dos o más "elementos". De modo que, puede afirmarse, entre el movimiento y la interacción hay indicación: el movimiento indica interacción. Por su parte, la "acción" es entendida, llanamente, como la manifestación de la capacidad de obrar. Pero, también, la acción designa un "hecho": es el efecto de hacer algo. Por ello, más que una mera ejecución, es una "fuerza". Así, entre movimiento y acción no hay sinonimia sino implicación: moverse implica hacer algo (y, evidentemente, no puede uno hacer algo sin que acaezcan efectos inconmensurables en otros).

Por tanto, el cuerpo que se mueve no es tan solo un cuerpo que "está-ahí" puesto entre la naturaleza y la sociedad (lo Otro). El cuerpo en movimiento es un cuerpo en acción y es, por ende, un cuerpo en "interacción"; o, de otro modo, todo cuerpo está en relación de acciones y toda relación de acciones es una relación de fuerzas que (se) modifican. He aquí lo que nos conviene de la noción relaciones de poder elaborada por Foucault: "Lo que caracteriza al poder es que pone en juego relaciones entre individuos -o entre grupos, [ya que] vivir en sociedad es vivir en tal forma que la acción sobre otras acciones es posible y en efecto se da" $(2005$ pp.42, 48). Estamos hablando, respecto a los cuerpos que se mueven, de un "conjunto de acciones que inducen otras y se siguen de otras". El poder como "lo que se ejerce sobre las cosas y da la habilidad de modificarlas, usarlas, consumirlas, destruirlas; un poder que surge de aptitudes directamente inherentes al cuerpo o transmitidas por medios exteriores" (Foucault, 2005 p. 42). 
Así que, si la interacción es una condición necesaria de nuestra existencia, hay que preguntarse por las "formas" en las que tal interacción se presenta (o expresa). Nos preguntamos ¿cómo se mueve un cuerpo?, o más precisamente, ¿qué modos de movimiento puede un cuerpo? Llamamos modos de movimiento a esas particulares maneras de realizarlo, dirigirlo (o darle intención), determinarlo y caracterizarlo. Sin duda, estos modos nos advierten tanto sobre la forma de poder que se ejerce, el tipo de interacción que se "induce", como sobre las circunstancias que envuelven la experiencia corporal y, por tanto, las características de la subjetividad que es producida.

Ahora bien, entre estos "modos" existen tres que resultan importantes y de fácil identificación entre los discursos epistemológicos y pedagógicos de la educación física, la recreación y el deporte: el modo técnico (relativo a la "técnica"), el modo práctico (referente a la "práctica") y el modo habitual (que concierne al "hábito"). Por supuesto, ha de esperarse que su estudio diga mucho más de lo que ha quedado circunscrito convencionalmente a los tres campos citados $y$, a su vez, que contribuya a mostrar las múltiples relaciones que estos tienen con otros campos y temáticas (como la ética, la política y la economía). En lo que resta de este escrito, debido a que resulta pertinente para el tema central que convoca esta revista y sobre todo por la falta de espacio que tenemos, trataremos únicamente el modo práctico.

Lo primero para decir es que el concepto "práctica" es bastante difícil de aprehender. Nos aproximamos a un concepto que ha suscitado lo que se llama, a veces de forma vaga, "pragmatismo", una especie de pensamiento "especial" al que se le adjudica el ser "pensamiento inmediato" o, particularmente, una forma de actuar que solo tiene en cuenta las (rápidas) utilidades en el "mundo real". De otra parte, este es un concepto que tiende a diferenciarse radicalmente del concepto "teoría", pero no en un sentido antagonista sino complementario en tanto la práctica es la aplicación de la teoría. Así mismo, ha habido una división del conocimiento en saberes prácticos y especulativos. Empero, puede que la unión lingüística implique algo más que usos con aires de familia.

Otro asunto implícito, necesario para esta exploración de lo que podría estar contenido en lo que hemos llamado el modo práctico de movimiento (o uso práctico del cuerpo) es que la práctica (praktiké) -termino amplio- remite a lo práctico (praktikós) como suposi- ción de facilitación y, por ende, de beneficio. En suma, lo práctico es lo adecuado (praktós). De esta forma, hay una fuerza semántica que obedece a un sentido de «conveniencia» que no puede obviarse. Ahora, sobre estas generalidades, en nuestro tiempo y en nuestro idioma podemos, al menos, encontrar tres nociones a propósito de la práctica:

1) En primer lugar, tenemos la idea de que "práctica" es la realización repetida de un ejercicio cualquiera, es decir, cualquier movimiento, cualquier acción se puede realizar una y otra vez. Etimológicamente es lo que se concibe como "ejercicio repetido de un arte u oficio" (Gómez, 1995 p. 557). Estamos en el aspecto verbal del término, para lo cual sería más apropiado, entonces, decir "practicar" (verbo transitivo). Esta noción es un aspecto clave del aprendizaje, y es aplicable tanto a lo que se conoce como ejercicio mental o virtual, como al llamado ejercicio real.

Esta interesante diferencia permite que no ubiquemos el concepto "práctica" con exclusividad en las acciones observables o, en términos de Parlebas (2001), en el comportamiento motor. En efecto, se trata de encontrar relevancia a unos ejercicios en el pensamiento y a un "entrenamiento" en la realidad. Foucault (2002) lo expone de manera magistral en el curso del Collège de France de 1981-1982, dedicado a la "inquietud de sí" desde las prácticas. Los términos que utiliza para la diferenciación de estas prácticas son la meditatio y la exercitatio. A partir de su análisis, queda claro que ya sea una práctica mental, como el cálculo matemático o la praemeditatio malorum, o una práctica real, como la "abstinencia, privación o resistencia física", el verbo practicar es aplicable a cualquier actividad humana.

En este sentido, encontramos una primera característica del modo práctico de moverse: se trata de "ejercitar" constantemente el cuerpo o repetir muchos actos para adiestrarse en la ejecución de una actividad cualquiera para el fin que le corresponda. En pocas palabras, intentar el "dominio" de movimientos.

2) Una segunda acepción es aquella que sigue a la anterior en un sentido, si se quiere, "causal". En efecto, se trata de la noción de "destreza 
adquirida con este ejercicio" (Gómez, 1995 p. 557); la práctica como "experiencia" creada por la repetición (de actos virtuales o reales). Las relaciones entre esta acepción y la de experiencia nos obligarían a entrar en aspectos teóricos que no queremos tratar por el momento; bástenos con decir que entre las nociones de experiencia, aquella que se refiere a una especie de acumulación, de ganancia o de efecto permite equipararla con la práctica; además, es por todos sabido el valor de la experiencia en la ciencia y la filosofía en cuanto a la adquisición del conocimiento.

La práctica es, pues, lo que se adquiere, lo que se obtiene, lo que sucede al uso práctico del cuerpo expuesto en el aparte anterior. Pero, en este mismo sentido, nos encontramos con una segunda característica del uso práctico del cuerpo: suposición de "conocimiento" como efecto (ya sea de una habilidad física o motriz, ya de una aprehensión "mental" o un "convencimiento"). Es decir, el movimiento práctico prevé para quien lo lleva a cabo un cumplimiento formal, una adquisición, una especie de perfeccionamiento o exactitud; pero no se trata de una acción vencida o finalizada (como en el caso de la técnica): por el contrario, volviéndonos sobre la primera característica citada, el uso práctico del cuerpo requiere una constante "ejercitación" (como si no dejara de adquirirse e, incluso, como si se llegara a perder por dejar de ejercitarse).

3) Finalmente, existe una tercera noción que ha sido frecuentemente utilizada en el ámbito de la educación física; el profesor Víctor Jairo Chinchilla lo expone diciendo que entiende por práctica "las acciones del cuerpo orientadas a fines, espontáneos o sistemáticos, que caracterizan la actividad de la educación física, a diferencia de las prácticas mentales de cálculo o las prácticas comunicativas" (2005, p. 108). Pero ¿acaso cuando la acción corporal es sistemática o espontánea no realiza también una acción mental y comunicativa? ¿Acaso se está sugiriendo un tipo de acción "impensada" o se están demeritando las cargas mentales y sociales de toda acción? ¿De algún modo se está pretendiendo obviar las manifestaciones de incomodidad o placer que los educandos sienten al llevar a cabo una acción, además de sus constantes cuestionamientos sobre la utilidad de estas acciones para la vida cotidiana, a la que se ven enfrentados necesariamente?

Esta última noción trata de la aplicación, realización o empleo de un "saber teórico". Esto podría hacernos desviar de la tesis que hasta ahora hemos presentado del cuerpo como un todo en el que se manifiestan irremediablemente aspectos biológicos, psicológicos y sociales; pero aun así vale la pena detenernos un poco porque la "utilización práctica" de las teorías (o bien, de principios teóricos) es de imprescindible importancia para la vida social humana. En la moral no basta con querer ser o decir que se quiere hacer tal o cual acción: es necesario hacerla; por ejemplo, ayudar al desvalido. Se nos escapa de las manos discutir la existencia del bien y del mal, lo que deseamos anotar es que moralmente estás obligado a hacer lo que dices, de lo contrario qué sentido tendría decirlo (esto es lo que se llama coherencia). Desde los griegos la moral es eminentemente una práctica.

Del mismo modo, la economía y la política son consideradas ciencias prácticas. En efecto, no tiene sentido que el economista plantee ciertas teorías con relación a los modos de producir, distribuir, cambiar y consumir lo producido si no son aplicadas; la absurda negación a un tipo de economía distinta a la capitalista ha hecho que esas otras formas de vida no capitalistas pierdan fuerza y vigencia; nos hemos "habituado" a unas acciones económicas (pagar, recibir pago, apropiarse de la tierra, vender, arrendar, hipotecar, etc.) que nos imprimen una forma muy particular de relacionarnos y de entender y manipular la naturaleza. En cuanto a la política, es más fácil aún darnos cuenta de la intención práctica de los debates entre senadores. Para no alargarnos más, bástenos recordar las palabras que Jürgen Habermas expuso en cuanto a la relación teoría-praxis para el materialismo histórico:

La teoría incluye una doble relación entre teoría y praxis: investiga, por una parte, el contexto histórico de constitución de una situación de intereses a la que aún pertenece la teoría, por así decirlo, a través del acto de conocimiento; $\mathrm{y}$, por otra parte, investiga el contexto histórico de acción sobre el que la teoría puede ejercer una influencia que orienta la acción. En un caso se trata de la praxis social que en tanto que síntesis social hace posible el conocimiento; en el otro de una praxis política 
que conscientemente aspira a subvertir el sistema de instituciones existentes. (1987 pp. 13-14) ${ }^{8}$

Como tal, ni la práctica se opone a la teoría ni la teoría se subordina a la práctica. Tampoco plantear sus diferencias y similitudes debe hacernos entrar en concepciones dualistas del cuerpo. Digámoslo así, sencillamente: el cuerpo planea y el cuerpo hace; existe un "movimiento del pensamiento" y un "movimiento de la materia" y ambos están en las delimitaciones del cuerpo.Y, además, ambos pueden realizarse de modo práctico.

Finalmente, en tanto esta tercera noción de práctica se refiere a la ejecución o realización de una acción, diremos que la "práctica" remite a la noción de acción, de llevar a cabo algo, por lo cual puede decirse que se trata de una "actividad sincrónica". Queremos decir con esto que la práctica no es una actividad que se realice de modo prolongado, a la cual llamaríamos "actividad diacrónica", es decir, la actividad que tiene lugar "a través" o "a lo largo del" tiempo. Lo que llamamos "actividad diacrónica" está más cerca de la noción de "hábito" que de la práctica, y para ser más específicos conviene reconocer que esta vez es más apropiado hablar de "prácticas", en plural.

Las prácticas son "actividades sincrónicas" en el sentido en el que se realizan "a veces": son actuales en un momento y un espacio muy precisos y dejan de ser por otro lapso desde el que pueden volver a realizarse. Este intermedio en el momento de realización de la práctica hace que esta adquiera una característica particular, la tercera característica del uso práctico del cuerpo: es momentánea, "actualizable", "esporádica", determinada temporalmente, sucede en "ocasiones"

8 Aunque autores como Freire conciben que "la praxis es en el marxismo la unión de la teoría con la práctica" (Ferrater, 2001, p. 2877), somos fieles a la traducción al español del texto de Habermas.

9 Como ejemplo, valga citar el juego en la vida adulta de Occidente. Los adultos no juegan todo el tiempo. Esta "actividad" está destinada a ciertos momentos y a ciertas horas. Igual pasa con la danza y el baile. El ciudadano común tan solo lleva a cabo estas "prácticas" en ocasiones. Pero, para no generar malentendidos, las "actividades" no están predeterminadas como diacrónicas o sincrónicas. Ni el juego ni la danza son en-sí "prácticas" o "hábitos", lo mismo que el viajar para un comerciante o un piloto, por ejemplo, resulta de hecho "habitual", mientras que para un oficinista tan solo se da en las vacaciones.

\section{Suspensión}

Como se ha pretendido mostrar, el modo práctico de moverse en el mundo, un modo que no puede ser concebido como especialidad de los cuerpos-hombres, resulta mucho más complejo (y, por tanto, atractivo) de lo que usualmente se cree si se estudia analíticamente, conforme su empleo en el lenguaje pero, indefectiblemente, de acuerdo al movimiento mismo que pueden los cuerpos. Si se restringe su indagación a los contextos educativos de un profesional que se supone ha sido formado (o capacitado) para cierto tipo de labor, su riqueza conceptual puede verse afectada tanto como las mismas acciones de estos profesionales. Precisamente, empezar a distinguir a qué hace referencia el movimiento más allá de la operatividad (fisiológica), ha de conducir al cambio de paradigma frente a las posibilidades laborales o, inclusive, existenciales de los licenciados en Educación Física, Recreación y Deporte.

Lo que aquí apenas hemos mostrado no pretende ser conclusivo sino, antes bien, suscitativo, para dar curso a investigaciones más detalladas. Se ha expuesto un horizonte de investigación respecto al cuerpo y al movimiento, en el cual se ha argumentado el axioma según el cual los hombres somos cuerpos que se mueven en un mundo de cuerpos en movimiento; y sobre este, de forma muy sucinta, se ha particularizado al cuerpo como un fenómeno múltiple o tetravalente (cuerpo sin órganos, cuerpo cultural, cuerpo singular y cuerpo sujeto) y al movimiento como una realidad existencial de interacción transformadora y productora de sujetos (debido a la experiencia corporal).

Sobre el movimiento se ha dicho, además, que no se realiza como un simple cambio mecánico de lugar, sino que (incluso este desplazamiento espacial) sucede en "modos" distintos que se pueden (y deben) estudiar minuciosamente. Entre estos modos, se ha explorado el modo práctico y, de él, se han esbozado tres características: trata de una ejercitación constante para el dominio de ciertos movimientos, supone como resultado la adquisición o el perfeccionamiento de una "habilidad" o "conocimiento", y es sincrónico o está determinado temporalmente (a diferencia de lo que podría decirse, superficialmente, del hábito).

Dejándose anunciados el modo técnico y el modo habitual, es prudente decir que son solo dos modos de los que posiblemente pueden seguir "descubriéndose". Pero, además, que no son en absoluto la única orientación investigativa que puede hacerse, más aún cuando 
se afirma que los cuestionamientos conceptuales sobre el cuerpo y el movimiento implican un sentido existencial imprescindible para comprender y transformar nuestras formas de vivir. En el océano de interrogantes ya se divisan altas olas como el tiempo, el ocio, la territorialidad, la identidad y la libertad, por nombrar solo unas pocas.

\section{Referencias}

Bateson, G. (2002)Espíritu y naturaleza. Buenos Aires: Amorrortu Editores.

Chinchilla, V. (2005) Elementos sobre epistemología y enseñanza de la educación física. Revista Lúdica Pedagógica, volumen 2(10). Bogotá: Universidad Pedagógica Nacional, 104-112.

Deleuze, G. (2006) Diferencia y repetición. Buenos Aires:. Amorrortu Editores.

Deleuze, G. (2005) La inmanencia: una vida... Pensamiento y Experimentación. Bogotá: Carpe Diem Editores y Tejer, 11-15.

Deleuze, G. y Parnet, C. (2004) Diálogos. España: Pre-Textos.

Deleuze, G. y Guattari, F. (1997) Mil mesetas. Capitalismo y esquizofrenia. España: Pre-Textos.

Deleuze, G. y Guattari, F. (2005) ¿Qué es la Filosofía? Barcelona: Editorial Anagrama.

Díaz Velasco, A. (2007) ¿Qué nos insinúa la «experiencia corporal»? Revista Lúdica Pedagógica, volumen 2(12). Bogotá: Universidad Pedagógica Nacional, 86-97.

Díaz Velasco, A. (2008) Elogio del movimiento (Parte I). Revista Lúdica Pedagógica, volumen 1(13). Bogotá: Universidad Pedagógica Nacional, 60-72.

Díaz Velasco, A. (2009) "Los hombres" como cuerpos, el cuerpo: una multiplicidad. Revista Lúdica Pedagógica, volumen 2(14). Bogotá: Universidad Pedagógica Nacional, 44-52.

Díaz Velasco, A. (2010) Elogio del movimiento (Parte II). Revista Lúdica Pedagógica, volumen 2(15). Bogotá: Universidad Pedagógica Nacional, 136-147.

Díaz Velasco, A. (2011) De la política de lo mental a la experiencia corporal. Revista Lúdica Pedagógica, volumen 2(16). Bogotá: Universidad Pedagógica Nacional, 123-154.

Ferrater Mora, J. (2001) Diccionario de Filosofía. Barcelona: Editorial Ariel.

Foucault, M. (2002) La hermenéutica del sujeto. Curso en el Collège de France (1981-1982). México: Fondo de Cultura Económica.

Foucault M. (2005) El sujeto y el poder. Pensamiento y Experimentación. Bogotá: Carpe Diem Editores y Tejer.

Gómez de Silva, G. (1995) Breve diccionario etimológico de la lengua española. México: Fondo de Cultura Económica.
Habermas, J. (1987) Teoría y praxis. Estudios de filosofía social. Madrid: Tecnos.

López Austin, A. (2008) Cuerpo humano e ideología. México: UNAM, Instituto de Investigaciones Antropológicas.

McLaren, P. (1997) Pedagogía crítica y cultura depredadora. Políticas de oposición en la era posmoderna. España: Ediciones Paidós Ibérica.

Nancy, J.L. (2003) Corpus. Madrid: Arena Libros.

Parlebas, P. (2001) Juegos, deportes y sociedades. Léxico de praxiología motriz. Barcelona: Editorial Paidotribo.

Pinzón, C. y Suárez, R. (1992) Las mujeres lechuza. Historia, cuerpo y brujería en Boyacá. Colombia: Instituto Colombiano de Antropología e Historia (Icanh) y Cerec.

Searle, J. (2009) Actos de habla. Ensayo de filosofía del lenguaje. Madrid: Ediciones Cátedra.

Séneca. (1984) Cartas morales a Lucilio (Vol. II). Traducción del latín de Jaime Bofill y Ferro. Argentina: Ediciones Orbis.

Turner, B. (2007) Los avances recientes en la teoría del cuerpo. Recuperado el 8 de agosto del 2008 en http:// dialnet.unirioja.es/servlet/articulo?codigo $=768110$.

Viveiros de Castro, E. (2003). Perspectivismo y multinaturalismo en la América indígena. En A. Chaparro y C. Schumacher (Eds.), Racionalidad y discurso mítico. Bogotá: Centro Editorial Universidad del Rosario, Icanh. pp. 191-243. 